\title{
Treatment of acute pancreatitis with protease inhibitors administered through intravenous infusion: an updated systematic review and meta-analysis
}

Takeshi Seta ${ }^{1,4}$, Yoshinori Noguchi ${ }^{2}$, Satoru Shikata ${ }^{3}$ and Takeo Nakayama ${ }^{4^{*}}$

\begin{abstract}
Background: The intravenous use of protease inhibitors in patients with acute pancreatitis is still controversial. The purpose of this study was to evaluate the effectiveness of protease inhibitors intravenously administered to prevent pancreatitis-associated complications.

Methods: We updated our previous meta-analysis with articles of randomized controlled trials published from January 1965 to March 2013 on the effectiveness of protease inhibitors for acute pancreatitis. A systematic search of PubMed, EMBASE, the Cochrane Library, and Japana Centra Revuo Medicina was conducted. In addition, Internet-based registries (ClinicalTrials.gov, controlled-trials.com, UMIN, JMACCT, and JAPIC) were used to search for on-going clinical trials. Furthermore, references of review articles and previously published meta-analyses were handsearched. The main outcome of interest was the overall mortality rate from acute pancreatitis.

Results: Seventeen trials were selected for analysis. Overall, protease inhibitors did not achieve a significant risk reduction in mortality (pooled risk difference $[\mathrm{RD}],-0.02$; $95 \%$ Confidence Interval $[\mathrm{Cl}],-0.05$ to 0.01 ; number needed to treat [NNT], 74.8) with low heterogeneity. A subgroup analysis in moderate to severe pancreatitis (defined by control mortality rate $[C M R]>0.10$ ) did not show a significant effect of protease inhibitors to prevent death (pooled RD, $-0.03 ; 95 \% \mathrm{Cl},-0.07$ to 0.01 ; NNT, 1603.9) with low heterogeneity. An additional subgroup analysis of two trials with CMR $>0.20$ (i.e., low quality) revealed a significant risk reduction.
\end{abstract}

Conclusion: The present meta-analysis re-confirmed that there is no solid evidence that supports the intravenous use of protease inhibitors to prevent death due to acute pancreatitis.

Keywords: Acute pancreatitis, Protease inhibitors, Mortality, Control mortality rate, Complication

\section{Background}

Acute pancreatitis is characterized by sudden abdominal pain and elevated serum concentrations of pancreatic enzymes. Overall mortality has been reported to be approximately 5 percent for acute pancreatitis and 20 percent for necrotizing pancreatitis [1,2]. Mild acute pancreatitis is generally treated with supportive care including pain control, intravenous fluids, and correction of electrolyte and metabolic abnormalities. A meta-analysis of eight trials

\footnotetext{
* Correspondence: t-nakayama@umin.ac.jp

${ }^{4}$ Department of Health Informatics, Kyoto University School of Public Health, Yoshida-Konoe, Sakyo-ku, Kyoto, Kyoto 606-8501, Japan

Full list of author information is available at the end of the article
}

revealed that enteral nutrition significantly reduced mortality, multiple organ failure, systemic infections, and the need for surgery compared with parenteral nutrition [3]. Furthermore, other meta-analyses that have been conducted on the effectiveness of acute pancreatitis treatments showed that the use of suitable analgesics effectively relieved pain [4], and that $\mathrm{H}_{2}$ receptor antagonists did not improve clinical outcomes of acute pancreatitis [5].

The role of protease inhibitors in the treatment of mild to severe acute pancreatitis is still unclear, although previous studies have demonstrated a marginal reduction in mortality. In particular, continuous regional arterial infusion of protease inhibitors was shown to be 
effective for acute necrotizing or severe pancreatitis in observational studies [6-8], as well as in a randomized controlled trial (RCT) [9]. In 2004, we conducted a metaanalysis of 10 RCTs with a total sample size of 1,036 [10] to evaluate the effectiveness of intravenous use of protease inhibitors for acute pancreatitis. The main outcome was the effectiveness of protease inhibitors to prevent death due to acute pancreatitis, and secondary outcomes were prevention of pancreatic pseudocyst, intra-abdominal abscess, and surgical intervention. Our analysis revealed no improvement in all outcomes. Moreover, protease inhibitors did not significantly reduce the mortality in the trials with control mortality rate (CMR) equal to or less than 0.10 , but might reduce the mortality with CMR more than 0.10 .

The purpose of the present study was to update the body of evidence on the effectiveness of intravenous use of protease inhibitors for acute pancreatitis.

\section{Methods}

A systematic review of meta-analyses was conducted and the results were described according to the PRISMA statement [11].

\section{Literature search}

First, we systematically searched PubMed, EMBASE, the Cochrane Library, and Japana Centra Revuo Medicina (the largest database of Japanese articles) for articles of RCTs published from January 1965 to March 2013 (search date: April, 2013) on the effectiveness of protease inhibitors used to treat acute pancreatitis. The electronic database search was conducted using a combination of Medical Subject Heading terms and text words "protease inhibitors" and "acute pancreatitis". Next, we searched Internet-based clinical trial registries, ClinicalTrials.gov [12] and controlled-trials.com [13], as well as all the three trial registries available in Japan, UMIN [14], JMACCT [15], and JAPIC [16] (search date: April, 2013) for ongoing RCTs using the same criteria. References of review articles and previously published meta-analyses were handsearched.

\section{Inclusion and exclusion criteria}

Given that the purpose of the present study was to update the body of evidence regarding the effectiveness of intravenous use of protease inhibitors for acute pancreatitis, the following inclusion criteria were set: 1) randomized placebo-controlled trials of protease inhibitors administered through intravenous infusion; and 2) written in all languages. No restrictions were placed on severity of pancreatitis or type of protease inhibitors. Furthermore, we excluded trials in which 1) both intervention and control groups were administered protease inhibitors; 2) protease inhibitors were administered by intra-arterial or intra- abdominal infusion; 3) subjects included patients with chronic pancreatitis; 4) pancreatitis was noted after endoscopic retrograde cholangiopancreatography (ERCP); 5) patients were administered frozen plasma; 6) the goal was to investigate basic medical science (e.g., pancreatic enzyme research); 7) patients had human immunodeficiency virus; 8) efficacy of antibiotics was being evaluated; 9) patients included post-operative cases; and 10) oral administration of protease inhibitors.

No restrictions were placed on patient age, sex, or cause of acute pancreatitis. Articles in the form of a conference proceeding or full paper were also included. One author (TS) selected articles to be included for analysis, and the other authors verified the process.

\section{Outcome measures}

The effectiveness of protease inhibitors for acute pancreatitis was evaluated based on the primary outcome of death due to acute pancreatitis, and secondary outcomes including relief from pain, pseudocyst formation, formation of intra-abdominal abscess, surgical intervention, paralytic small bowel obstruction, and other major complications including multiple organ failure.

\section{Study characteristics}

Study design, participants, mode of intervention, and definition of outcomes were faithfully extracted from the articles included in the final analysis. We also confirmed the status of industrial support for each trial.

\section{Control mortality rate (CMR)}

We calculated CMR (defined as the number of deaths in the control group divided by the number of patients in the control group) for each RCT.

\section{Quality assessment for selected trials and data extraction}

The quality of each trial retrieved was assessed by the Jadad method [17] on the basis of whether the trial was randomized, the appropriateness of the randomization process (if applicable), whether the trial was doubleblinded, the appropriateness of the double-blinding process (if applicable), and withdrawals/dropouts. Each item was assigned a score of 0 or 1 , and the total score ranged from 0 to 5 . In the present meta-analysis, trials with a Jadad score greater than 3 were defined as highquality trials. Furthermore, we evaluated risk of bias for each trial and assessed the quality of the body of evidence using the Grading of Recommendations Assessment, Development, and Evaluation (GRADE) system for grading evidence [18].

One author (TS) conducted the quality assessment and extraction of analyzable data, which were verified by the other authors. Disagreement or uncertainty was resolved among all the authors. 


\section{Statistical analysis}

We calculated the risk difference (RD), i.e., risk in the intervention group minus risk in the control group, for the primary outcome of the trials. A negative RD indicated risk reduction due to intervention, and a positive $\mathrm{RD}$, risk increase due to intervention (range, -1 to 1 ). Whether the treatment or control was favored was denoted by the signs "+" and "-", respectively. Then, the weighted pooled estimates were calculated for binary data. A fixed-effect model weighted by the Mantel-Haenszel (M-H) method was used for pooling RD [19], followed by a test of homogeneity. Homogeneity among trials was assessed using the $\mathrm{I}^{2}$ test [20]. We defined $\mathrm{I}^{2}$ value $<25 \%$ as low, 25 to $50 \%$ as moderate, and $>50 \%$ as high heterogeneity.

If the hypothesis of homogeneity was rejected, a random-effect model using the DerSimonian-Laird (DL) method was employed [21]. The potential for publication bias was examined by the funnel plot method [22] using the Begg's [23] or Egger's test [24]. The number needed to treat (NNT, 1/RD) to prevent one adverse event was also used as a measure of treatment effect. We used the "number needed to treat benefit (NNTB; the number of patients needed to be treated for one additional patient to benefit)" for a positive NNT, and the "number needed to treat harm (NNTH; the number of patients needed to be treated for one additional patient to be harmed)" for a negative NNT. When the upper or lower limit of the 95\% confidence interval (CI) was infinity, the NNT scale including infinity was used [25]. All statistical analyses were performed with Stata statistical software [26]. Results were expressed as means and $95 \%$ CIs, unless otherwise indicated. $\mathrm{P}<0.05$ was considered statistically significant.

\section{Results}

Trial selection and features (Figure 1 and Additional file 1: Table S1)

Our database search yielded 96 articles, and handsearching of bibliographies of retrieved meta-analyses and clinical guidelines yielded additional three and two articles, respectively. There were no on-going trials in the registries. Of the 101 articles, 24 met the inclusion criteria [27-50]; no multiple publications were found. Reviewers' selection of relevant articles was completely the same, and there was no unsuitable study for inclusion by authors' consensus. The 77 excluded articles described ERCP studies $(n=36)$, studies in which a protease inhibitor was administered to both intervention and control groups $(\mathrm{n}=8)$, arterial infusion studies $(\mathrm{n}=6)$, and other $(\mathrm{n}=27)$ (Figure 1). Next, all authors read the selected 24 articles, reaching a consensus to exclude seven more articles $[27,38-40,45,48,50]$ including two in which a protease inhibitor was administered to both intervention and control groups $[30,45]$, two that were published as comments
$[38,50]$, one in which glucagon was given to the control group [39], one published as an editorial $(n=1)$ [40], and one reporting an ERCP study [48]. In the end, a total of 17 articles [27-29,31-37,41-44,46,47,49] were selected for analysis.

The present meta-analysis of the retrieved competent studies included 15 RCTs from the handsearch [27,28, $31-37,41-43,46,47,49]$, one [29] from a previous metaanalysis [51], and one [44] from guidelines [52], with the total sample size of 1,697 patients. Of the 15 articles manually searched, 10 [33,34,37,41-44,46,47,49] were used in our previous meta-analysis [10].

All articles evaluated death due to acute pancreatitis, in addition to other outcomes such as pain relief $(n=2)$ [31,49], pseudocyst formation $(n=5) \quad[29,37,41,43,46]$, intra-abdominal abscess formation $(n=4)[37,41,43,46]$, surgical intervention $(n=3)[44,47,49]$, paralytic small bowel obstruction $(n=3)[41,47,49]$, and other complications $(n=5)[36,37,43,46,47]$. Of the 17 articles, 11 $[29-31,33-36,41,42,44,46,47]$ were conducted in a multicenter setting, and six $[27,28,32,37,42,49]$ in a singlecenter setting. Sixteen articles were published as a full paper [27-29,31-37,41-43,46,47], and one as an abstract only [44]. Fourteen articles were written in English [27-29,31,33-35,37,41,43,44,46,47,49], two in German $[32,42]$, and one in French [36]. Eleven trials used aprotinin [27-29,31-37,41], and six trials used gabexate mesilate $[42-44,46,47,49]$, all against the placebo control. Four articles $[36,41,47,49]$ described tangible outcomes in the method section, whereas 13 provided no description [27-29,31-35,37,42-44,46]. The sample size was pre-calculated only in one article [47]. Acute pancreatitis was defined as clinical manifestation with elevated serum pancreatic enzyme levels in 11 articles $[27-29,34,35,37,41,43,46,47,49]$, or as clinical manifestation with elevated urine pancreatic enzyme levels in two [32,33]; no description regarding the definition was found in the remaining four articles [31,36,42,44]. Nine articles described sources of funding or medicine support from industries $[27,29,31,34,35,37,41-44]$. The severity of acute pancreatitis was reported using the Ranson's score in two articles [47,49], or Acute Pathophysiology and Chronic Health Evaluation (APACHEII) score in one article [49]. In addition to these, we evaluated the severity of acute pancreatitis according to CMR in the present analysis, and found that 10 articles had CMR >0.10 [27,28,34-36,41,43,44,47,49]. No articles mentioned the presence or absence of adverse events. Seven articles observed death due to acute pancreatitis as the primary outcome [27,28,32-35,47]. Six articles reported no secondary outcome [27,28,32-35], while one article observed surgical intervention and bowel obstruction as the secondary outcomes [47]. Ten articles reported undistinguishable outcomes [29,31,36, 


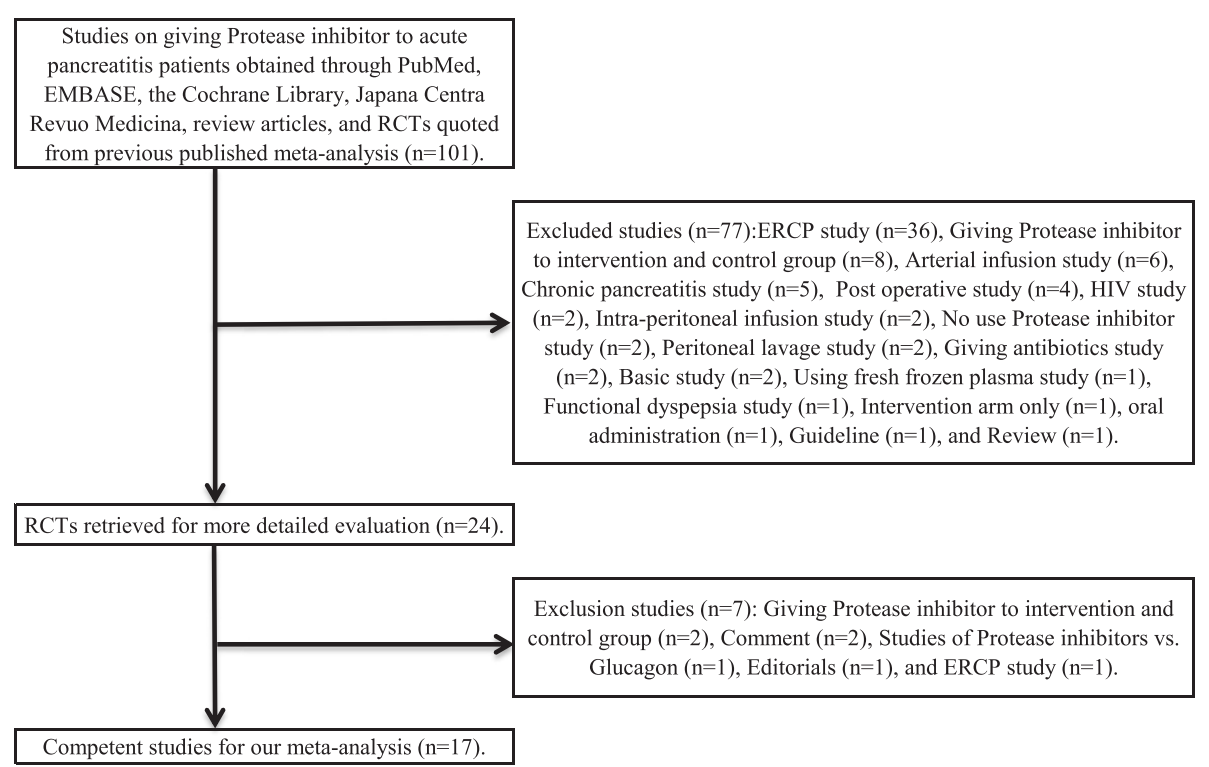

Figure 1 Flow of randomized controlled trials through the process of retrieval and inclusion in the meta-analysis comparing protease inhibitors with placebo for acute pancreatitis. The numbers in parentheses are the 'Jadad scores' of the individual trials. 95\% Cl, 95\% confidence interval. ERCP, endoscopic retrograde cholangiopancreatography.

37,41-45,49]. We performed quality of evidence assessment and found death, pseudocyst, intra-abdominal abscess, and any major complications to be low quality, and abdominal pain, surgical intervention, and bowel obstruction to be very low quality. Table 1 shows heterogeneity of each outcome with $\mathrm{I}^{2}$ values.

\section{Quality assessment (Additional file 1: Table S1 and Table 2)}

The overall mean Jadad score was 2.1 (range 0-5). The mean Jadad score increased to 2.6 if three RCTs with a 0 score $[28,32,43]$ were excluded. Six trials $[31,34$, $35,37,46,47]$ were considered high quality (Jadad score $\geq 3$ ), with the mean Jadad score of 3.7. With respect to risk of bias of each trial, two described random allocation $[46,47], 13$ described allocation concealment [27,29, $31,33-37,41,42,44,46,47], 13$ described blinding [27,29,31, $33-37,41,42,44,46,47]$, three described outcome data addressed $[44,46,47]$, and four described selective outcome reporting [36,41,47,49]; no other bias was described. One RCT described intention to treat (ITT) analysis [47]. The quality of each outcome in terms of evidence was graded low to very low.

\section{Primary outcome: preventing death (Tables 1 and 3)}

All trials reported death due to acute pancreatitis (Table 1 and Figures 2 and 3), 11 with aprotinin [27-29, $31-37,41]$, and six with gabexate mesilate $[42-44,46,47,49]$. Overall results of the 17 trials showed no significant risk reduction (low heterogeneity) in mortality with the use of protease inhibitors. Furthermore, subgroup analyses revealed no significant results (Table 3 ).

\section{Secondary outcomes}

\section{Preventing abdominal pain}

Two trials reported that protease inhibitors (aprotinin [31] and gabexate mesilate [49]) were effective in preventing abdominal pain $[31,49]$. Overall results showed a significant risk reduction (high heterogeneity) with protease inhibitor use. However, the subgroup analysis of one of the two trials deemed high quality [31] revealed no significant effectiveness.

\section{Preventing pseudocyst formation}

Five trials (three for aprotinin $[29,37,41]$ and two for gabexate mesilate $[43,46])$ reported that protease inhibitors were effective in preventing pseudocyst formation. Overall results showed no significant risk reduction (low heterogeneity).

\section{Preventing intra-abdominal abscess formation}

Four trials (two for aprotinin $[37,41]$ and two for gabexate mesilate $[43,46]$ ) reported that protease inhibitors were effective in preventing intra-abdominal abscess formation. Overall results showed no significant risk reduction (low heterogeneity).

\section{Preventing surgical intervention}

Three trials, all of which evaluated the use of gabexate mesilate, reported that the protease inhibitor was effective in preventing surgical intervention $[44,47,49]$. Overall results showed a significant risk reduction (moderate to high heterogeneity). However, the subgroup analysis of one of the three trials deemed high quality [47] revealed no significant effectiveness. 
Table 1 Evaluation of evidence quality of using each RCT

\begin{tabular}{|c|c|c|c|c|c|c|c|c|}
\hline Author & Year & Allocation & Concealment & Blinding & $\begin{array}{l}\text { Outcome data } \\
\text { addressed }\end{array}$ & $\begin{array}{l}\text { Selective outcome } \\
\text { reporting }\end{array}$ & Other bias & ITT analysis \\
\hline Skyring A [27] & 1965 & no & yes & yes & no & no & no & no \\
\hline Ryall RJ [28] & 1966 & no & no & no & no & no & no & no \\
\hline Trapnell JE [29] & 1967 & no & yes & yes & no & no & no & no \\
\hline Bachrach WH [31] & 1968 & no & yes & yes & no & no & no & no \\
\hline Möller C [32] & 1969 & no & no & no & no & no & no & no \\
\hline Baden H [33] & 1969 & no & yes & yes & no & no & no & no \\
\hline Trapnell JE [34] & 1974 & no & yes & yes & no & no & no & no \\
\hline MRC Multicenter Trial [35] & 1977 & no & yes & yes & no & no & no & no \\
\hline Gauthier A [36] & 1978 & no & yes & yes & no & yes & no & no \\
\hline Imrie CW [37] & 1978 & no & yes & yes & no & no & no & no \\
\hline MRC Multicenter Trial [41] & 1980 & no & yes & yes & no & yes & no & no \\
\hline Freise J [42] & 1986 & no & yes & yes & no & no & no & no \\
\hline Yang CY [43] & 1987 & no & no & no & no & no & no & no \\
\hline Goebell H [44] & 1988 & no & yes & yes & yes & no & no & no \\
\hline Valderrama R [46] & 1992 & yes & yes & yes & yes & no & no & no \\
\hline Büchler M [47] & 1993 & yes & yes & yes & yes & yes & no & yes \\
\hline Chen HM [49] & 2000 & no & no & no & no & yes & no & no \\
\hline
\end{tabular}

$R C T$ randomozed controlled trial; ITT intension to treat.

\section{Preventing bowel obstruction}

Three trials (one for aprotinin [41] and two for gabexate mesilate $[47,49])$ reported that protease inhibitors were effective in preventing bowel obstruction. Overall results showed a significant risk reduction (moderate to high heterogeneity). However, the subgroup analysis of one of the three trials deemed high quality [47] revealed no significant effectiveness.

\section{Preventing major complications}

Five trials (two for aprotinin [36,37] and three for gabexate mesilate $[43,46,47])$ reported that protease inhibitors were effective in preventing some complications. These complications included respiratory failure, renal failure, gastrointestinal bleeding, metabolic failure (details unknown), sepsis, or hypoxia $[43,46]$. Three studies defined complications as pancreatitis-related complications or unknown $[33,37,47]$. Overall results showed no significant risk reduction (low heterogeneity).

\section{Publication bias (Figure 4)}

The funnel plot was not symmetric; however, neither one of the statistical tests revealed significant publication bias $(\mathrm{p}=0.653$ and $\mathrm{p}=0.736$, respectively).

\section{Sensitivity analysis for trial quality (Tables 4 and 5 )}

Using the main outcome, i.e., overall mortality from acute pancreatitis, we performed a sensitivity analysis according to the Jadad score. The effect size and level of statistical significance did not decrease with increasing trial quality. We then performed another sensitivity analysis according to CMR. In all trials and trials with CMR $<0.20$, no significant effectiveness of protease inhibitors was shown. However, a significant effectiveness was found when trials were limited to those with $\mathrm{CMR}>0.20$.

\section{Discussion}

In this study, we conducted a systematic review of RCTs to update our previous meta-analysis of 2004 on the effectiveness of intravenous infusion of protease inhibitors for acute pancreatitis. As the present literature search retrieved no additional RCTs since 2004 up to March 2013, we analyzed a new set of articles including those that had not been identified in the previous meta-analysis [10]. The present analysis re-confirmed the validity of evidence reported to date, as follows: 1) treatment with protease inhibitors did not significantly reduce the mortality rate from acute pancreatitis; 2) subgroup analysis of trials with CMR greater than 0.20 showed limited effectiveness of protease inhibitors in preventing death; 3) protease inhibitors showed no significant effectiveness even in outcomes other than preventing death. Moreover, given that there are no on-going trials regarding the use of protease inhibitors for acute pancreatitis, no new evidence supporting their effectiveness is expected to emerge for the next few years.

In the previous meta-analysis, we evaluated prevention of death due to acute pancreatitis, formation of pancreatic 
Table 2 Effectiveness for acute pancreatitis with protease inhibitors

\begin{tabular}{|c|c|c|c|c|c|c|c|c|c|c|}
\hline \multirow[t]{3}{*}{ Outcomes } & \multirow{3}{*}{$\begin{array}{l}\text { No. of } \\
\text { studies }\end{array}$} & \multicolumn{5}{|c|}{ Pooled risk difference } & \multirow{3}{*}{$\begin{array}{c}\text { NNT } \\
95 \% \mathrm{Cl}\end{array}$} & \multirow{3}{*}{$\begin{array}{c}\text { Heterogeneity } \\
I^{2} \text { value(\%) }\end{array}$} & \multirow{3}{*}{$\begin{array}{l}\text { Statistical method } \\
\text { by effect model }\end{array}$} & \multirow{3}{*}{$\begin{array}{c}\text { Quality of a } \\
\text { body of evidence }\end{array}$} \\
\hline & & \multirow[t]{2}{*}{ Value } & \multicolumn{2}{|c|}{$95 \% \mathrm{Cl}$} & \multicolumn{2}{|c|}{ Value } & & & & \\
\hline & & & Lower & Upper & NNTB & NNTH & & & & \\
\hline Death & 17 & -0.02 & -0.05 & 0.01 & 74.8 & & NNTH 62.4 to $\infty$ to NNTB 23.4 & 0 & $\mathrm{M}-\mathrm{H}$ & \\
\hline High quality studies & 6 & -0.02 & -0.06 & 0.02 & & 624.6 & NNTH 24.6 to $\infty$ to NNTB 26.7 & 34.1 & $\mathrm{M}-\mathrm{H}$ & \\
\hline Aprotinin & 11 & -0.01 & -0.05 & 0.02 & 89.3 & & NNTH 38.8 to $\infty$ to NNTB 20.8 & 0 & $\mathrm{M}-\mathrm{H}$ & \\
\hline Gabexate mesilate & 6 & -0.02 & -0.07 & 0.03 & 54.3 & & NNTH 33.3 to $\infty$ to NNTB 14.9 & 31.1 & $M-H$ & \\
\hline Daily dosage $>900 \mathrm{mg}$ of GM & 5 & -0.02 & -0.09 & 0.04 & 55.2 & & NNTH 8.3 to $\infty$ to NNTB 14.C & 47.0 & $M-H$ & \\
\hline Daily dosage $>1500 \mathrm{mg}$ of GM & 2 & -0.09 & -0.33 & 0.15 & 33.6 & & NNTH 17.8 to $\infty$ to NNTB 8.6 & 79.0 & D-L & low \\
\hline Mild pancreatitis & 7 & 0.00 & -0.03 & 0.04 & & 177.5 & NNTH 24.5 to $\infty$ to NNTB 33.9 & 0 & $\mathrm{M}-\mathrm{H}$ & \\
\hline Moderate to severe pancreatitis & 10 & -0.03 & -0.07 & 0.01 & & 1604 & NNTH 23.0 to $\infty$ to NNTB 23.7 & 19.7 & $\mathrm{M}-\mathrm{H}$ & \\
\hline Severe pancreatitis & 2 & -0.19 & -031 & -0.08 & 5.2 & & 3.2 to 12.7 & 0 & $M-H$ & \\
\hline With sponsor & 9 & -0.02 & -0.06 & 0.02 & 67.0 & & NNTH 43.0 to $\infty$ to NNTB 18.8 & 15.0 & $\mathrm{M}-\mathrm{H}$ & \\
\hline Without sponsor & 8 & -0.02 & -0.06 & 0.03 & 68.4 & & NNTH 31.9 to $\infty$ to NNTB 16.5 & 0 & $M-H$ & \\
\hline Abdominal pain & 2 & -0.26 & -0.40 & -0.13 & 3.9 & 2.5 to 9.6 & 85.0 & $D-L$ & & var \\
\hline High quality study & 1 & -0.14 & -0.32 & 0.03 & 6.9 & & NNTH 30.1 to $\infty$ to NNTB 3.1 & Uncalculatable & $M-H$ & very low \\
\hline Pseudocyst formation & 5 & -0.00 & -0.05 & 0.03 & 298.6 & & NNTH 27.3 to $\infty$ to NNTB 23.1 & 0 & $\mathrm{M}-\mathrm{H}$ & low \\
\hline Intra-abdominal abscess formation & 4 & -0.01 & -0.04 & 0.02 & 113.2 & & NNTH 65.3 to $\infty$ to NNTB 30.3 & 0 & $\mathrm{M}-\mathrm{H}$ & low \\
\hline Surgical intervention & 3 & -0.08 & -0.17 & -0.00 & 11.8 & & 6.0 to 443.8 & 60.5 & DOL & netser \\
\hline High quality study & 1 & 0.00 & -0.10 & 0.11 & & 225.8 & NNTH 8.9 to $\infty$ to NNTB 9.7 & Uncalculatable & $\mathrm{M}-\mathrm{H}$ & 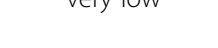 \\
\hline Bowel obstruction & 3 & -0.06 & -0.12 & -0.00 & 6.3 & & 4.0 to 14.5 & 58.8 & D-L & ato \\
\hline High quality study & 1 & -0.03 & -0.08 & 0.02 & 33.9 & & NNTH 44.2 to $\infty$ to NNTB 12.3 & Uncalculatable & $\mathrm{M}-\mathrm{H}$ & very low \\
\hline Any major complications & 5 & -0.01 & -0.08 & 0.06 & 76.4 & & NNTH 15.7 to $\infty$ to NNTB 11.1 & 0 & $\mathrm{M}-\mathrm{H}$ & low \\
\hline
\end{tabular}

$N N T$ number needed to treat; NNTB number needed to treat benefit; $N N T H$ number needed to treat harm; $C l$ confidence intervals; $M-H$ mantel-haenszel; $D-L$ dersimonian-laird; GM, gabexate mesilate. 
Table 3 Subgroup analyses on the primary outcome (death due to acute pancreatitis)

\begin{tabular}{lccccc}
\hline No & Subgroup & Trial $(\mathbf{n})$ & Citations & Effectiveness & Heterogeneity \\
\hline 1 & High-quality & 6 & {$[31,34,35,37,46,47]$} & No significant & Moderate \\
2 & Aprotinin & 11 & {$[27-29,31-37,41]$} & No significant & Low \\
3 & Gabexate mesilate & 6 & {$[42-44,46,47,49]$} & No significant & Low to moderate \\
4 & Gabexate mesilate daily administrated dosage>900mg & 5 & {$[42,44,46,47,49]$} & No significant & Low to moderate \\
5 & Gabexate mesilate daily administrated dosage>1500mg & 2 & {$[47,49]$} & No significant & Low to moderate \\
6 & Trials with CMR $\leqq 0.10$ & 7 & {$[29,31-33,37,42,46]$} & No significant & Low to moderate \\
7 & Trials with CMR>0.10 & 10 & {$[27,28,34-36,41,43,46,47,49]$} & No significant & Low to moderate \\
8 & Trials with CMR>0.20 & 2 & {$[34,49]$} & No significant & Low to moderate \\
9 & Trials with industrial support & 9 & {$[27,29,31,34,35,37,41-43]$} & No significant & Low to moderate \\
10 & Trials with industrial support & 8 & {$[28,32,33,36,44,46]$} & No significant & Low to moderate \\
\hline
\end{tabular}

High-quality was defined as Jadad score $>3$ points; CMR control mortality rate.

pseudocysts, intra-abdominal abscess, and surgical intervention as outcomes. In the present analysis, we added prevention of abdominal pain due to acute pancreatitis and bowel obstruction. The present analysis had a larger sample size of 1,697 in total, compared to 1,036 in the previous analysis. The effectiveness of protease inhibitors stratified by CMR level was similarly examined in both the previous and present analyses. In the previous analysis [10], five $[34,43,44,47,49]$ of 10 selected articles [31,33, $34,37,42-44,46,47,49]$ were with CMR $>0.10$ and showed limited effectiveness. In the present analysis, $10[27,28$, $34-36,41,43,44,47,49]$ of 17 selected articles were with CMR $>0.10$ and showed no significant effectiveness. On the other hand, the subgroup analysis of articles with
CMR $>0.20[34,49]$ revealed a significant therapeutic effect. However, it is suspected that low-quality trials that included potentially severe patients might have exaggerated the effectiveness. In fact, the mean Jadad score was 2.5 in RCTs with $C M R>0.20$, and 1 point in those with $\mathrm{CMR}>0.30$, suggesting that it is very likely that low-quality trials provided a veneer of effectiveness for severe patients.

The quality of evidence was assessed for each trial by two methods, one that used the conventional Jadad scoring system, and the other based on the GRADE system. The mean Jadad score ( 2.1 points) was low, and the majority of RCTs were deemed low to moderate quality, except for six trials $[31,34,35,37,46,47]$ that were deemed

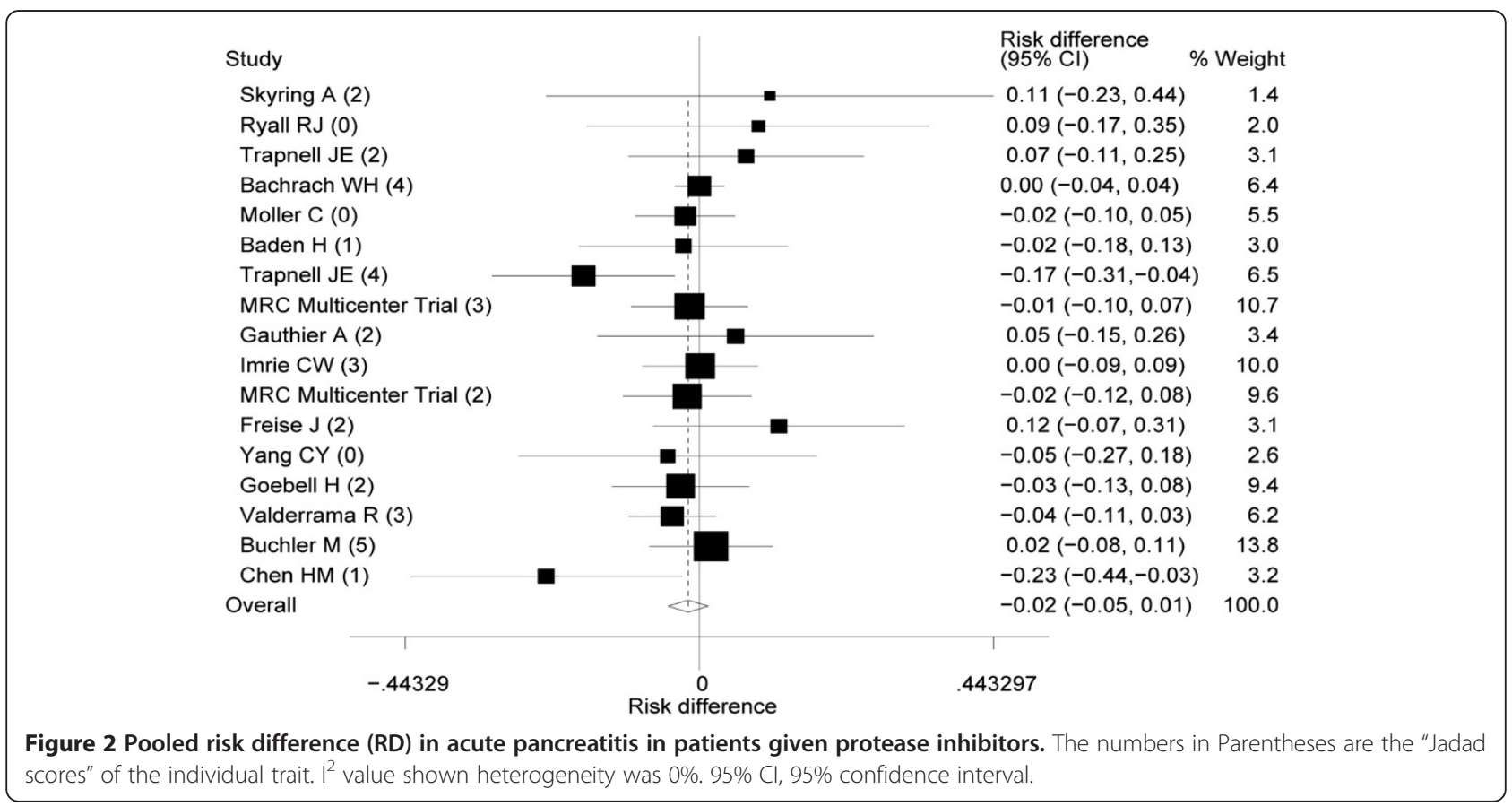




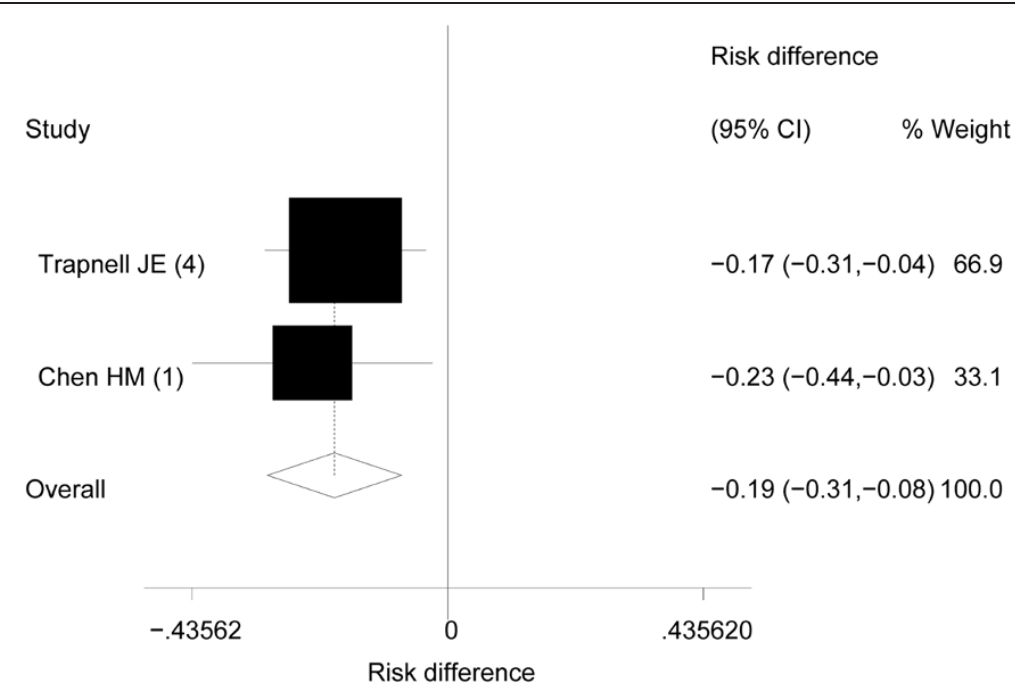

Figure 3 Pooled risk difference (RD) in acute severe pancreatitis in patients given protease inhibitors. The numbers in Parentheses are the "Jadad scores" of the individual trait. $I^{2}$ value shown heterogeneity was $0 \% .95 \% \mathrm{Cl}, 95 \%$ confidence interval.

high quality with a Jadad score of $\geq 3$. We then used the GRADE system to evaluate each RCT in terms of risk of bias (random allocation, allocation concealment, blinding, outcome data addressed, selective outcome reporting, and others). Furthermore, we graded the quality of the body of evidence for each clinical outcome using the GRADE system in addition to the Jadad scoring system to further strengthen quality of evidence assessment. Handling of outcome data was likely to become a nest of bias, reporting bias, and ITT analysis were mentioned in three articles [44,46,47], four articles [36,41,47,49], and one article [47], respectively. The quality of RCTs included in the present review was low in general, and hence, the bodies of evidence and result estimations are both likely to be low in quality. We also checked each article in terms of whether there were descriptions regarding industrial support, tangible outcome, and sample size calculation in the methodology. With respect to industrial support, we found no significant difference in effectiveness according to the status of industrial support; however, eight articles [28,32,33,36,44,46,47,49] provided no description regarding funding or medicine support, and thus the actual status was unknown. With respect to tangible outcomes, only four of 17 articles [36,41,47,49] provided descriptions in the methods sections, and no article reported the presence or absence of adverse events. Sample size calculation was described in only one article [47]. The CONSORT statement [51], which

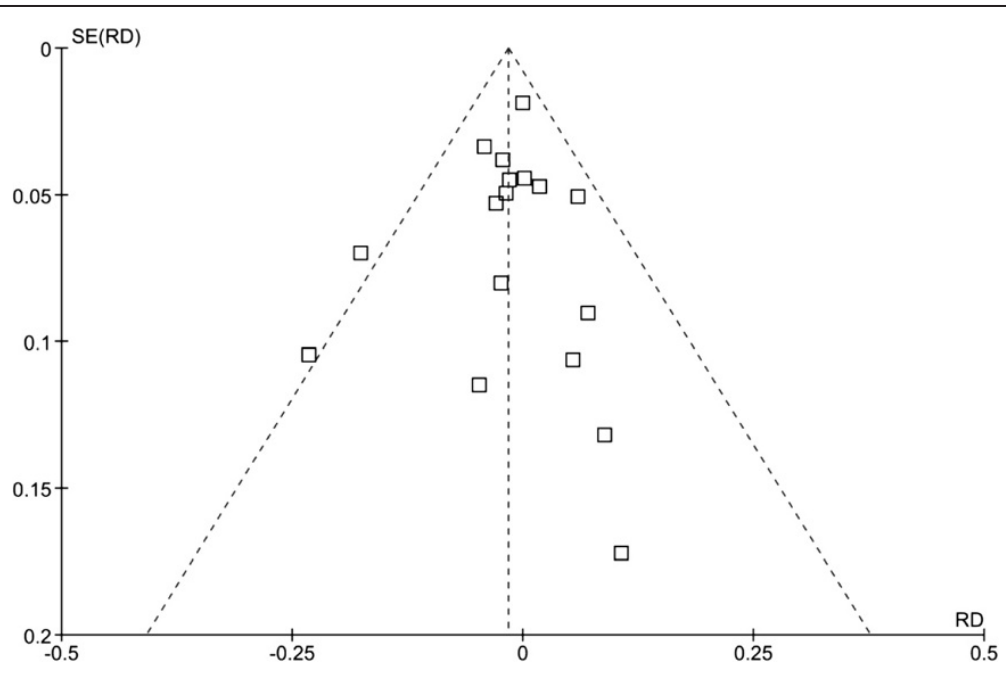

Figure 4 Publication bias of trials reporting acute pancreatitis in patients given protease inhibitors. RD, Risk Difference; SE, Standard Error. 
Table 4 Sensitivity analysis for trial quality

\begin{tabular}{cccc}
\hline & No. of studies & Pooled RD & $\mathbf{9 5 \%} \mathbf{C l}$ \\
\hline Overall & 17 & -0.02 & -0.05 to 0.01 \\
Jadad score $\geqq 1$ & 14 & -0.02 & -0.05 to 0.01 \\
Jadad score $\geqq 2$ & 12 & -0.01 & -0.04 to 0.02 \\
Jadad score $\geqq 3$ & 6 & -0.02 & -0.06 to 0.02 \\
\hline
\end{tabular}

$R D$ risk difference; $\mathrm{Cl}$ confidence interval.

specifies reporting of the primary outcome and sample size calculation, might have led to improved quality of reporting [52,53], although previous studies found inappropriateness or deficit of reporting common in published articles [54,55]. It was likely for the authors of adopted trials to select only the preferable results to report, among many outcomes measured.

This study has some limitations worth noting. First, the subgroup analysis which aimed to consider disease severity was not based on established criteria of severity. Instead, we defined CMR $>0.10$ as an arbitrary and retrospective index to indicate moderate to severe pancreatitis. Prospective indices such as the Atlanta Classification [56], Ranson's criteria [57], or APACHE-II score [58] were used only in two RCTs $[47,49]$. Although CMR is advantageous in that it can be easily calculated after trial completion, clinical interpretation of case severity based on CMR requires prudent consideration, as it is subject to factors such as care quality provided at each institution. Unfortunately, accurate evaluations of the severity of acute pancreatitis are difficult at the entry of each trial. With reluctance, the present study used CMR as a surrogate measure of severity because only two trials [34,49] had used either the Ranson's score or APACHE-II score.

The second limitation was the low quality of the individual studies evaluated by our review. The overall mean Jadad score was 2.1 (range, 0-5; three RCTs scored a 0 $[28,32,43])$, which meant that the overall quality of the studies was low to moderate. Our previous meta-analysis [10] showed that protease inhibitors were effective when CMR was greater than 0.10 , while this was true only when CMR was greater than 0.20 in the present study. In our previous report [10], we calculated the APACHEII scores using a multiple logistic equation described by Knaus et al. [58]. We also found that $\mathrm{CMR}=0.10$ scored

Table 5 Sensitivity analysis for control mortality rate

\begin{tabular}{cccc}
\hline & No. of studies & Pooled RD & $\mathbf{9 5 \% ~ C l}$ \\
\hline Overall & 17 & -0.02 & -0.05 to 0.01 \\
$C M R \geqq 0.10$ & 10 & -0.03 & -0.07 to 0.01 \\
$C M R \geqq 0.20$ & 2 & -0.19 & -0.31 to -0.08 \\
\hline
\end{tabular}

$R D$ risk difference; $C$ confidence interval; $C M R$ control mortality rate. roughly six points for the APACHE-II score method. On the APACHE-II scale (highest score: 67 points), we discovered that our patients scored 6 points when they presented with high-grade fever, hyperventilation, acidosis, renal dysfunction, leukocytosis, and deterioration of consciousness. One study has already validated the severity of acute pancreatitis with the APACHE-II score system [58]. CMR $>0.20$ for acute pancreatitis may be worse than these physical conditions, and we would be interested to test whether protease inhibitors would be effective in preventing death or other complications. Although meta-analyses of the two trials with CMR $>0.20$ showed that protease inhibitors were effective, reporting quality and heterogeneity should be taken into account when interpreting the results $[34,49]$.

Third, the treatment modality of protease inhibitors was confined to intravenous administration. The present study excluded trials of intra-arterial or intra-abdominal infusion of protease inhibitors because the main objective was to update our previous meta-analysis [10]. Accordingly, we did not evaluate the effectiveness of protease inhibitors according to their various administrations. Further systematic reviews and meta-analyses on these modalities of administrations are expected in future. Future RCTs in this field should examine the effectiveness of protease inhibitors administered through intravenous or intra-arterial infusion, particularly among patients with severe acute pancreatitis.

\section{Conclusions}

This updated meta-analysis re-confirmed that there is no solid evidence to support the use of intravenous protease inhibitors for preventing death, abdominal pain, pseudocyst formation, intra-abdominal abscess formation, surgical intervention, bowel obstruction, or any complications of pancreatitis excluding post-ERCP complications. Future trials on the effectiveness of intravenous protease inhibitor using established severity criteria (i.e., APACHE-II score system) should be promoted, particularly for patients with severe acute pancreatitis.

\section{Additional file}

Additional file 1: Table S1. Characteristics of primary trials.

\section{Abbreviations}

RCT: Randomized controlled trial; CMR: Control mortality rate; UMIN: University hospital medical information network; JMACCT: Japan medical association clinical trial registry; JAPIC: Japan pharmaceutical information center; RD: Risk difference; ERCP: Endoscopic retrograde cholangiopancreatography; GRADE: Grading of recommendations assessment, development and evaluation; M-H: Mantel-Haenszel; D-L: DerSimonian-Laird; NNT: Number needed to treat; NNTB: Number needed to treat benefit; NNTH: Number needed to treat harm; Cl: Confidence Interval; ITT: Intention to treat; APCHE: Acute pathophysiology and chronic health evaluation; SE: Standard error. 


\section{Competing interests}

Potential competing interest: The authors declare that they have no competing interest.

\section{Authors' contributions}

TS contributed to the study design, literature search and selection, data extraction and analysis, and writing the draft. YN, SS, and TN contributed to the literature search and selections, data extraction and analysis. All authors read and approved the final manuscript.

\section{Guarantor of the article}

Takeshi Seta, MD.

\section{Support}

This study was supported by the grant-in-aid by the Ministry of Health, Labour and Welfare, Japan.

\section{Author details}

${ }^{1}$ Division of Gastroenterology and Hepatology, Japanese Red Cross Society Wakayama Medical Center, 4-20, Komatsubara-dori, Wakayama, Wakayama 640-8558, Japan. ²Division of General Internal Medicine, Japanese Red Cross Society Nagoya Daini Red Cross Hospital, Myoken-cho 2-9, Showa-ku, Nagoya-city 466-8650, Aichi, Japan. ${ }^{3}$ Department of Family medicine, Mie Prefectural Ichishi Hospital, 616 Minami ieshiro, Hakusan-cho, Tsu-city, Mie 515-3133, Japan. ${ }^{4}$ Department of Health Informatics, Kyoto University School of Public Health, Yoshida-Konoe, Sakyo-ku, Kyoto, Kyoto 606-8501, Japan.

Received: 21 June 2013 Accepted: 14 May 2014

Published: 30 May 2014

\section{References}

1. Cavallini G, Frulloni L, Bassi C, Gabbrielli A, Castoldi L, Costamagna G, De Rai P Di Carlo V, Falconi M, Pezzilli R, Uomo G, Prolnf-AISP Study Group: Prospective multicentre survey on acute pancreatitis in Italy (Prolnf-AISP): results on 1005 patients. Dig Liver Dis 2004, 36:205-211.

2. Banks PA, Freeman ML: Practice parameters Committee of the American college of gastroenterology. practice guidelines in acute pancreatitis. Am J Gastroenterol 2006, 101:2379-2400.

3. Al-Omran M, Albalawi ZH, Tashkandi MF, Al-Ansary LA: Enteral versus parenteral nutrition for acute pancreatitis. Cochrane Database Syst Rev 2010, 20, CD002837.

4. Brownfield E: Pain management. In Making Healthcare Safer: A Critical Analysis of Patient Safety Practices. AHRQ Evidence Report/Technology Assessment Number 43. www.ahrq.gov/clinic/ptsafety/pdf/chap37.pdf.

5. Morimoto T, Noguchi Y, Sakai T, Shimbo T, Fukui T: Acute pancreatitis and the role of histamine-2 receptor antagonists: a meta-analysis of randomized controlled trials of cimetidine. Eur J Gastroenterol Hepatol 2002, 14:679-686.

6. Takeda K, Matsuno S, Sunamura M, Kakugawa Y: Continuous regional arterial infusion of protease inhibitor and antibiotics in acute necrotizing pancreatitis. Am J Surg 1996, 17:394-398.

7. Takeda K, Yamauchi J, Shibuya K, Sunamura M, Mikami Y, Matsuno S: Benefit of continuous regional arterial infusion of protease inhibitor and antibiotic in the management of acute necrotizing pancreatitis. Pancreatol 2001, 1:668-673.

8. Imaizumi H, Kida M, Nishimaki H, Okuno J, Kataoka Y, Kida Y, Soma K, Saigenji K: Efficacy of continuous regional arterial infusion of a protease inhibitor and antibiotic for severe acute pancreatitis in patients admitted to an intensive care unit. Pancreas 2004, 28:369-373.

9. Piaścik M, Rydzewska G, Milewski J, Olszewski S, Furmanek M, Walecki J, Gabryelewicz A: The results of severe acute pancreatitis treatment with continuous regional arterial infusion of protease inhibitor and antibiotic: a randomized controlled study. Pancreas 2010, 39:863-867.

10. Seta T, Noguchi Y, Shimada T, Shikata S, Fukui T: Treatment of acute pancreatitis with protease inhibitors: a meta-analysis. Eur J Gastroentero Hepatol 2004, 16:1287-1293.

11. Moher D, Liberati A, Tetzlaff J, Altman DG, PRISMA Group: Preferred reporting items for systematic reviews and meta-analyses: the PRISMA statement. Ann Intern Med 2009, 151:264-269.

12. ClinicalTrials.gov: available from http://clinicaltrials.gov

13. Controlled-trials.com: available from http://www.controlled-trials.com.
14. UMIN: Japan: University Hospital Medical Information Network; available from http://www.umin.ac.jp/ctr/index-j.htm.

15. JMACCT: Japan Medical Association Clinical Trial Registry; available from https://dbcentre3.jmacct.med.or.jp/jmactr/App/JMACTRS01/JMACTRS01. aspx?kbn=4

16. JAPIC: Japan Pharmaceutical Information Center. available from http:// clinicaltrials.jp/user/cte_main.jsp.

17. Jadad AR, Moore RA, Carroll D, Jenkinson C, Reynolds DJ, Gavaghan DJ, McQuay HJ: Assessing the quality of reports of randomized clinical trials: is blinding necessary? Control Clin Trials 1996, 17:1-12

18. Guyatt GH, Oxman AD, Vist G, Kunz R, Brozek J, Alonso-Coello P, Montori V, Akl EA, Djulbegovic B, Falck-Ytter Y, Norris SL, Williams JW Jr, Atkins D, Meerpohl J, Schünemann HJ: GRADE guidelines: 4. Tating the quality of evidence-study limitations (risk of bias). J Clin Epidemio/ 2011, 64:407-415.

19. Greenland S, Robins JM: Estimation of a common effect parameter from sparse follow-up data. Biometrics 1985, 41:55-68.

20. Higgins JP, Thompson SG, Deeks JJ, Altman DG: Measuring incomsistency in meta-analysis. BMJ 2003, 327:557-560

21. DerSimonian R, Laird N: Control Clin Trials 1986, 7:177-188.

22. Light RJ, Pilemer DB: Summing up: the science of reviewing research. Cambridge, MA: Harvard University Press: 1984

23. Begg CB, Mazumdar M: Operating characteristics of a rank correlation test for publication bias. Biometrics 1994, 50:1088-1101.

24. Egger M, Davey Smith G, Schneider M, Minder C: Bias in meta-analysis detected by a simple, graphical test. BMJ 1997, 315:629-634.

25. Altman DG: Confidence intervals for the number needed to treat BMJ 1998, 317:1309-1312

26. Stata/SE 11 for Windows. College Station, Texas: Stata Corporation; 2009.

27. Skyring A, Singer A, Tornya P: Treatment of acute asylol: report of a controlled therapeutic trial. BMJ 1965, 2:627-629.

28. Ryall RJ: Discussion on acute pancreatitis with a report on a clinical trial of trasylol. Anglo Ger Med Rev 1966, 3:274-283.

29. Trapnell JE, Talbot CH, Capper WM: Trasylol in acute pancreatitis. Am J Dig Dis 1967, 12:409-412.

30. Baden $H$, Jordal $K$, Lund F, Zachariae F: A double-blind controlled clinical trial of Trasylol. Preliminary results in acute pancreatitis and in prophylaxis against postoperative pancreatitis. Acta Chir Scand Suppl 1967, 378:97-102.

31. Bachrach WH, Schild PD: A double-blind study of Trasylol in the treatment of pancreatitis. Ann N Y Acad Sci 1968, 146:580-592.

32. Möller C, Stjernvall L: Clinical trial with Trasylol against acute pancreatitis. Ann Chir Gynaecol Fenn 1969, 58:296-299.

33. Baden $\mathrm{H}$, Jordal $\mathrm{K}$, Lund F, Zachariae F: Prophylactic and curative action of Trasylol in pancreatitis. A double-blind trial. Scand J Gastroenterol 1969, 4:291-295.

34. Trapnell JE, Rigby CC, Talbot CH, Duncan EH: A controlled trial of Trasylol in the treatment of acute pancreatitis. Br J Surg 1974, 61:177-182.

35. Death from acute pancreatitis. M.R.C. multicentre trial of glucagon and aprotinin. Lancet 1977, 2:632-635.

36. Gauthier A, Gillet M, Di Costanzo J, Camelot G, Maurin P, Sarles H: Controlled therapeutic trial of aprotinin and glucagon in acute pancreatitis. Gastroenterol Clin Biol 1978, 2:777-784.

37. Imrie CW, Benjamin IS, Ferguson JC, McKay AJ, Mackenzie I, O'Neill J, Blumgart LH: A single-centre double-blind trial of Trasylol therapy in primary acute pancreatitis. Br J Surg 1978, 65:337-341.

38. Imrie CW: Medical treatment of acute pancreatitis. Gastroenterology 1978 75:766-767

39. Kirsch A, Werner U, Heinze D: Proteinase inhibiting agents and glucagon in acute pancreatitis. Zentralb/ Chir 1978, 103:291-303.

40. Soergel $\mathrm{KH}$ : Medical treatment of acute pancreatitis: what is the evidence? Gastroenterology 1978, 74:620-628.

41. Morbidity of acute pancreatitis: the effect of aprotinin and glucagon. Gut 1980, 21:334-339.

42. Freise J, Melzer P, Schmidt FW, Horbach L: Gabexate mesilate in the treatment of acute pancreatitis. Results of a Hannover multicenter double-blind study with 50 patients. Z Gastroenterol 1986, 24:200-211.

43. Yang CY, Chang-Chien CS, Liaw YF: Controlled trial of protease inhibitor gabexelate mesilate (FOY) in the treatment of acute pancreatitis. Pancreas 1987, 2:698-700.

44. Goebell H: Multicenter double-blind study of gabexate mesilate (Foy) given intravenously in low dose in acute pancreatitis [Abstract]. Digestion 1988, 40:83. 
45. Harada H, Miyake H, Ochi K, Tanaka J, Kimura I: Clinical trial with a protease inhibitor gabexate mesilate in acute pancreatitis. Int J Pancreatol 1991, 9:75-79.

46. Valderrama R, Pérez-Mateo M, Navarro S, Vázquez N, Sanjosé L, Adrián MJ, Estruch J: Multicenter double-blind trial of gabexate mesylate (FOY) in unselected patients with acute pancreatitis. Digestion 1992, 51:65-70.

47. Büchler M, Malfertheiner P, Uhl W, Schölmerich J, Stöckmann F, Adler G, Gaus W, Rolle K, Beger HG: Gabexate mesilate in human acute pancreatitis. German Pancreatitis Study Group. Gastroenterology 1993, 104:1165-1170.

48. Cicardi M, Testoni P, Bergamaschini L, Guzzoni S, Cugno M, Buizza M, Bagnolo F: Antiproteasic activity of $\mathrm{C} 1$ inhibitor. Therapeutic perspectives. Ann Ital Med Int 1994, 9:180-182.

49. Chen HM, Chen JC, Hwang TL, Jan YY, Chen MF: Prospective and randomized study of gabexate mesilate for the treatment of severe acute pancreatitis with organ dysfunction. Hepatogastroenterology 2000, 47:1147-1150.

50. Pezzilli R, Miglioli M: Multicentre comparative study of two schedules of gabexate mesilate in the treatment of acute pancreatitis. Italian Acute Pancreatitis Study Group. Dig Liver Dis 2001, 33:49-57.

51. Begg C, Cho M, Eastwood S, Horton R, Moher D, Olkin I, Pitkin R, Rennie D, Schulz KF, Simel D, Stroup DF: Improving the quality of reporting randomized controlled trials. The CONSORT statement. JAMA 1996, 276:637-639.

52. Plint AC, Moher D, Morrison A, Schulz K, Altman DG, Hill C, Gaboury I: Does the CONSORT checklist improve the quality of reports of randomized controlled trials? A systematic review. Med J Aust 2006, 185:263-267.

53. Hopewell S, Dutton S, Yu LM, Chan AW, Altman DG: The quality of reports of randomized trials in 2000 and 2006: a comparative study of articles indexed by PubMed. BMJ 2010, 340:c723.

54. Uetani K, Nakayama T, Ikai H, Yonemoto N, Moher D: Quality of reports on randomized controlled trials conducted in Japan: evaluation of adherence to the CONSORT statement. Inter Med 2009, 48:307-313.

55. Shikata S, Nakayama T, Yamagishi H: Quality of surgical randomized controlled trials for acute cholecystitis: assessment based on CONSORT and additional check items. J Hepatobiliary Pancreat Surg 2008, 15:297-303.

56. Bradley EL 3rd: A clinically based classification system for acute pancreatitis. Summary of the International Symposium on Acute Pancreatitis, Atlanta, Ga, September 11 through 13, 1992. Arch Surg 1993, 128:586-590.

57. Ranson JH, Rifkind KM, Roses DF, Fink SD, Eng K, Spencer FC: Prognostic signs and the role of operative management in acute pancreatitis. Surg Gynecol Obstet 1974, 139:69-81.

58. Knaus WA, Draper EA, Wagner DP, Zimmerman JE: APACHE II: a severity of disease classification system. Crit Care Med 1985, 13:818-829.

doi:10.1186/1471-230X-14-102

Cite this article as: Seta et al:: Treatment of acute pancreatitis with protease inhibitors administered through intravenous infusion: an updated systematic review and meta-analysis. BMC Gastroenterology 2014 14:102.

\section{Submit your next manuscript to BioMed Central and take full advantage of:}

- Convenient online submission

- Thorough peer review

- No space constraints or color figure charges

- Immediate publication on acceptance

- Inclusion in PubMed, CAS, Scopus and Google Scholar

- Research which is freely available for redistribution 